\title{
Maternal reports of child injuries in Canada: trends and patterns by age and gender
}

\author{
Dafna E Kohen, Hassan Soubhi, Parminder Raina
}

BC Injury Research and Prevention Unit, Centre for Community Child Health

Research, Department of Health Care and Epidemiology, University of British Columbia, and Centre for Health Services and Policy Research, University of British Columbia, Canada D E Kohen

BC Injury Research and Prevention Unit, Centre for Community Child Health Research and Department of Health Care and Epidemiology, University of British Columbia, Canada H Soubhi

BC Injury Research and Prevention Unit, Centre for Community Child Health

Research, Department of Health Care and Epidemiology, University of British Columbia, Centre for Health Services and Policy Research, University of British Columbia, and Centre for Community Health and Health Evaluation Research, British Columbia Research Institute for Children's and Women's Health, University of British Columbia, Canada P Raina

Correspondence to: Dr Dafna Kohen, BC Injury Research and Prevention Unit, L408-4480 Oak Street, Vancouver, BC V6H 3V4,

Canada (email:

injury@cw.bc.ca)

\begin{abstract}
Objectives-This study examines gender and age differences in maternal reports of injuries in a cross sectional group of children aged 0-11 years. The cause, nature, body part injured, and location of injury are explored, as are the associations with family socioeconomic indicators and associations with limitations in activities. Methods-Data for 22831 children and their families come from cycle 1 of the Canadian National Longitudinal Survey of Children and Youth collected in 1995. Descriptive analyses and $\chi^{2}$ tests for trends are used to examine injury variations by child gender and age. Logistic regressions are used to examine the relationship between socioeconomic indicators and injury and the associations between injury and limitations in activities.

Results-Consistent with findings from hospital data, boys experience more injuries than girls, and injuries increase with child age. Falls are the most common sources of maternally reported injuries, followed by scalds/poisonings for young children and sports injuries for school aged children. The majority of injuries occur in or around the home for young children, but at school for older children. For maternal reports of childhood injuries, single marital status is a risk factor for boys.

Conclusions-Maternally reported injuries occur in $10 \%$ of Canadian children and many of these are associated with limitations in activities. Preventative strategies should take both child age and gender into consideration.

(Injury Prevention 2000;6:223-228)
\end{abstract}

Keywords: maternal reports; limitations in activities; socioeconomic indicators

In many industrialized countries, unintentional injuries represent the leading cause of death for youth less than 20 years of age. ${ }^{1-3}$ In 1995, injuries were responsible for $57 \%$ of all deaths among young Canadians, whereas $5 \%$ of deaths were caused by cancer and $2 \%$ by infectious disease. ${ }^{4}$ Injury information is primarily supplied by mortality and hospitalization data, which tend to address severe injuries and include limited detail. Information concerning injuries treated in emergency departments, other outpatient settings, and those treated at home or left untreated is often unavailable. These "minor injuries" are often the cause of pain and temporary disability, and may be a precursor for more serious injuries. Therefore survey data including detailed information on severe and minor childhood injuries are valuable in the assessment of risk factors and conditions with the goal of injury prevention programming.

The types of serious injuries children suffer show distinct patterns across age groups and gender. ${ }^{15-7}$ These patterns reflect exposure to risk, the location and activities where children spend a majority of their time, as well as the child's level of development. ${ }^{78}$ The major cause of non-fatal injuries among infants and young children is falls ${ }^{9-11}$ and sports and recreational activities for older children and adolescents. From birth to 24 years of age boys are more likely to sustain injuries compared with girls, to be hospitalized because of injuries, and to suffer the most severe forms of injury. ${ }^{12}$ Gender differences also become more pronounced with age. ${ }^{167}$

Socioeconomic indicators, such as single marital status, low levels of maternal education, and living in conditions of poverty are factors associated with childhood injury. ${ }^{13-17} \mathrm{~A}$ steep social class gradient in mortality exists for unintentional injury, with children living in low income families being more likely to experience injury than children from higher income families. ${ }^{18-20}$

The first objective of this study was to describe the characteristics of maternally reported child injury by gender and age, including causes and types of injuries, body parts injured, and locations of injury events. The second objective was to examine the relationships between childhood injury and socioeconomic indicators, such as marital status, household income, and maternal education. The third objective was to examine the association between childhood injury and limitations in daily activities. All three objectives were investigated using data from cycle 1 of the National Longitudinal Survey of Children and Youth (NLSCY).

\section{Methods}

SURVEY

The NLSCY is a national prospective study designed to measure child wellbeing, health, and development. It is based on a random probability sample of Canadian residential households of children aged 0-11 years, excluding households situated in remote areas, First Nations Peoples' reserves, and institutional settings. Sampling frames for cycle 1 of the NLSCY (1995) included a main component based on Statistics Canada's Monthly Labour Force Survey (excluding the territo- 
ries) and an integrated component based on the 1994 National Population and Health Survey. In total, 15579 households participated: 12879 for the main component and 2700 for the integrated component.

The NLSCY response rate was $86.3 \%$ (13 439 respondents). Slight underrepresentation of census metropolitan areas, households with both parents aged 40 and over, and households with a parent with eight years or less of education was detected. Sample weights were applied to the data to account for unequal probabilities of selection, nonresponse (person and household level), and the age and gender distributions of the Canadian population. The current study focuses on a cross sectional sample of children aged 0-11 years from cycle 1 of the NLSCY.

SAMPLE SELECTION

One child aged $0-11$ years was randomly selected from eligible households. Information was obtained from the person most knowledgeable about that child, the mother for $91.3 \%$ of households. Of these, $89.9 \%$ were the child's biological mother and $1.4 \%$ were step, adoptive, or foster mothers. For ease of discussion, the person most knowledgeable will be referred to as the mother. Other children were selected at random, to a maximum of four per household. The mother was asked to complete a general questionnaire, a parent questionnaire, and a child questionnaire, providing basic demographic information about all household members, socioeconomic information about herself and her spouse, and extensive information about the selected children. A cross sectional sample of 22831 children aged 0-11 years was initially surveyed from November 1994 to June 1995 and will be followed up into adulthood with reassessments every two years.

VARIABLES

Family socioeconomic indicators included marital status (two parent family, single parent family), household income (<\$10 000-14 999; \$15 000-29 999; \$30 000-40 000), and maternal level of education (some high school, completed high school, more than high school).

Limitations of activities assessed current long term conditions or health problems preventing or limiting the child's participation in school, at play, or in other activities (yes/no).

Injury status was assessed by determining if the child had been injured within the past 12 months. Information was also collected about the number of injuries, the nature of injury, the body parts injured, and the cause of injury. Nature of injury included broken/fractured bones, burns/scalds, dislocations/sprains/ strains, cuts/scrapes/bruises, or "other" including concussions, poisonings, internal injury, dental injury, and multiple injuries. Body parts included facial, head and neck, upper extremities, lower extremities or "other" including back, spine, trunk, and multiple sites (grouped due to small sample sizes). Cause of injury was grouped into motor vehicle collision, bicycle accident, fall, sport, scald or poisoning, and an "other" category not specified by the parent.

Covariates included gender and the number of siblings $(0,1+)$.

ANALYSIS

Descriptive analyses and $\chi^{2}$ tests for trends were conducted to examine variations by gender and age (infants/toddlers 0-3 years; preschoolers 4-5 years; school aged 6-11 years) for the causes and nature of injuries, body part injured, and location of injuries. Logistic regressions examined associations between socioeconomic indicators and injury status as well as the association of injury status and limitations in daily activities. Sample weights were used for all analyses. Because the sampling method included more than one child per household, number of siblings was included as a covariate in each model to account for a possible type 1 error due to clustering.

\section{Results}

DESCRIPTIVE ANALYSIS

The proportion of boys (51\%) and girls (49\%) in the total sample was similar. The majority of children $(74 \%)$ lived in families with high household income $(>\$ 30000)$ while $8 \%$ lived in low household income families $(<\$ 14999)$. Fifteen per cent of children lived in single female headed households. The majority of the mothers $(66 \%)$ had more than a high school level of education while $16 \%$ had less than high school.

\section{INJURY STATUS}

From the total sample of 22831 children, $10 \%$ $(n=2288)$ were injured in the last 12 months ( $9 \%$ of girls and $11 \%$ of boys). For all age groups, female gender was associated with lower rates of injury (odds ratio (OR) 0.78, $95 \%$ confidence interval (CI) 0.72 to 0.85 ). Injuries increased with age $\left(\chi^{2}\right.$ (trend, $\left.\mathrm{df}=1\right)=$ $53.22, \mathrm{p}<0.05)$ and were reported in $8 \%$ of infants/toddlers, $9 \%$ of preschoolers, and $12 \%$ of school aged children. School aged children had significantly more injuries than infant/ toddlers and preschoolers $(\mathrm{p}<0.01)$. There was no significant difference between infants/ toddlers and preschoolers.

Further analyses were conduced by gender and age group where sample size allowed. For boys and girls the most common cause of injury was falls, followed by sports injuries (table 1). The most frequent types of injuries were cuts/scrapes/bruises, broken/fractured bones, and dislocations/sprains/strains. Injuries most commonly occurred in the upper extremities, the lower extremities, and the face. Boys experienced significantly more facial injuries and head or neck injuries. Injuries most frequently occurred inside and outside the child's home, and in school or daycare.

Analyses by age groups suggested that falls were the most common cause of injury for each age group (table 1 ) but decreased as children got older $\left(\chi^{2}\right.$ (trend, $\left.\left.\mathrm{df}=1\right)=72.83, \mathrm{p}<0.01\right)$. Cuts/scrapes/bruises were the most common types of injuries for all ages, followed by 
Table 1 Cause, nature, body part, and location of injury by gender and child age

\begin{tabular}{|c|c|c|c|c|c|}
\hline & $\begin{array}{l}\text { Boys (\%) } \\
(n=11 \quad 677)\end{array}$ & $\begin{array}{l}\text { Girls (\%) } \\
(n=11154)\end{array}$ & $\begin{array}{l}\text { Infants and } \\
\text { toddlers }(\%) \\
(n=7545)\end{array}$ & $\begin{array}{l}\text { Preschoolers (\%) } \\
(n=3909)\end{array}$ & $\begin{array}{l}\text { School aged (\%) } \\
(n=11 \text { 378) }\end{array}$ \\
\hline \multicolumn{6}{|l|}{ Cause of injury } \\
\hline Motor vehicle & $1 \dagger$ & $2 \dagger$ & $1 \dagger$ & $3+$ & $1 \dagger$ \\
\hline Bicycle & 6 & 4 & $2+$ & $4+$ & 6 \\
\hline Fall & 50 & 53 & 63 & 61 & $43^{\star \star}$ \\
\hline Sport & 15 & 16 & $2+$ & $2+$ & 26 \\
\hline Scald/poisoning & 8 & 7 & 11 & $7+\star \star$ & 6 \\
\hline "Other" not specified by parent & 21 & 18 & 21 & 23 & 18 \\
\hline \multicolumn{6}{|l|}{ Nature of injury } \\
\hline Broken/fractured bones & 22 & 27 & 13 & 19 & $30^{\star \star}$ \\
\hline Burn/scald & 5 & 4 & 8 & $3+$ & $3^{\star \star}$ \\
\hline Dislocation/sprain/strain & 12 & 19 & 13 & $8+$ & $19^{\star \star}$ \\
\hline Cut/scrape/bruise & 45 & 34 & 50 & 51 & $33^{\star \star}$ \\
\hline "Other" $\ddagger$ & 16 & 16 & 16 & 19 & 15 \\
\hline \multicolumn{6}{|l|}{ Body part injured } \\
\hline Facial & 22 & $17^{\star}$ & 31 & 28 & 12 \\
\hline Head or neck & 18 & $12^{\star}$ & 23 & 27 & 9 \\
\hline Upper extremities & 34 & 40 & 29 & 28 & 42 \\
\hline Lower extremities & 23 & 26 & 14 & 14 & 32 \\
\hline "Other" includes back, spine, trunk, and multiple sites & 3 & 5 & $3 \dagger$ & $3+$ & 5 \\
\hline \multicolumn{6}{|l|}{ Location of injury } \\
\hline Own home & 31 & 33 & 63 & 35 & $17^{\star \star}$ \\
\hline Outside home & 20 & 21 & 12 & 32 & 21 \\
\hline In or around private residence & 10 & 8 & 10 & 11 & 8 \\
\hline School/day care & 16 & 15 & $4 \dagger$ & $8+$ & 23 \\
\hline Sports facility & 8 & 10 & $1+$ & $2+$ & 15 \\
\hline "Other" category not specified by parent & 15 & 13 & 10 & 12 & 16 \\
\hline
\end{tabular}

${ }^{\star} \mathrm{p}<0.05,{ }^{\star \star} \mathrm{p}<0.01$, significance levels for $\chi^{2}$ tests of trend.

†Sample size $<30$, estimates may be unreliable.

¥"Other" category includes concussion, poison, internal injury, dental injury, multiple injuries, and other not specified by parent.

broken/fractured bones and dislocations/ sprains/strains. The number of cuts/scrapes/ bruises $\left(\chi^{2}\right.$ (trend, $\left.\left.\mathrm{df}=1\right)=65.72, \mathrm{p}<0.01\right)$ and burns/scalds $\left(\chi^{2}\right.$ (trend, $\left.\left.\mathrm{df}=1\right)=19.39, \mathrm{p}<0.01\right)$ decreased as children got older. However, more severe injuries such as broken/fractured bones increased with age $\left(\chi^{2}\right.$ (trend, $\left.\mathrm{df}=1\right)=78.25$, $\mathrm{p}<0.01$ ) occurring more frequently in school aged children than in the younger age groups.

Facial injuries were most common for infant/toddlers and preschoolers, followed by injuries to the upper extremities and injuries to the head and neck. School aged children sustained the majority of injuries to the upper and lower extremities, followed by the face. Injuries to the youngest groups of children occurred inside and outside the home, while the home was less frequently associated with injuries among older children $\left(\chi^{2}\right.$ (trend, $\left.\mathrm{df}=1\right)$ $=413.62, \mathrm{p}<0.01)$. For school aged children injuries more frequently occurred at school or at daycare.

FAMILY SOCIOECONOMIC INDICATORS

Single female headed families (OR 1.28, 95\% CI 1.11 to 1.47 ), household incomes of \$15-29 999 (OR 1.24, 95\% CI 1.02 to 1.52 ), and maternal levels of education greater than high school (OR 1.14, 95\% CI 1.04 to 1.25 ) were associated with an increased risk of injury for the total group.

Boys living in single female headed families were at greater risk of injury, but for girls injury was associated with high levels of maternal education (table 2). Girls were less likely to be injured regardless of age compared with boys. Maternal levels of education greater than high school were associated with increased risk of injury among school aged children.

Single female headship was associated with a greater likelihood of childhood injury for all ages. Medium and high levels of income were associated with an increased risk of injury for boys, with the highest risks for infants/toddlers and preschoolers. Maternal levels of education greater than high school were associated with an increased risk of injury for school aged children, with the risk of injury increasing by $29 \%$ for school aged boys (table 3).

Single female headship was not associated with an increased risk of injury among girls. Although not significant, high levels of household income may serve as a protective factor for female infants/toddlers and preschoolers, but as a risk factor for school aged girls. Levels of maternal education greater than high school were associated with higher risks of injuries for girls of all ages, but effects did not reach significance (table 3).

\section{LIMITATIONS IN ACTIVITIES}

In the total sample, $3.9 \%$ of children had limitations in their daily activities, and those injured were more likely to experience limitations (OR 1.28, 95\% CI 0.98 to 1.64 for boys and OR $1.46,95 \%$ CI 1.06 to 2.03 for girls). Injuries were significantly associated with limitations in daily activities for school aged children (OR 1.54, 95\% CI 1.22 to 1.95 ) but not for preschoolers or infants/toddlers.

When gender and age groups were examined, injuries were associated with limitations in activities for boys of preschool and school age. This effect was significant for school aged boys (OR $0.57,95 \%$ CI 0.25 to 1.30 for infants/toddlers; OR $1.49,95 \%$ CI 0.83 to 2.69 for preschoolers; and OR 1.38, 95\% CI 1.01 to 1.88 for school aged). Similarly, injuries were associated with limitations in daily activities for school aged girls (OR $0.44,95 \%$ CI 0.13 to 1.48 for infants/toddlers; OR $0.33,95 \% \mathrm{CI}$ 0.05 to 2.18 for preschoolers; and OR 1.85, $95 \%$ CI 1.29 to 2.64 for school aged girls). 

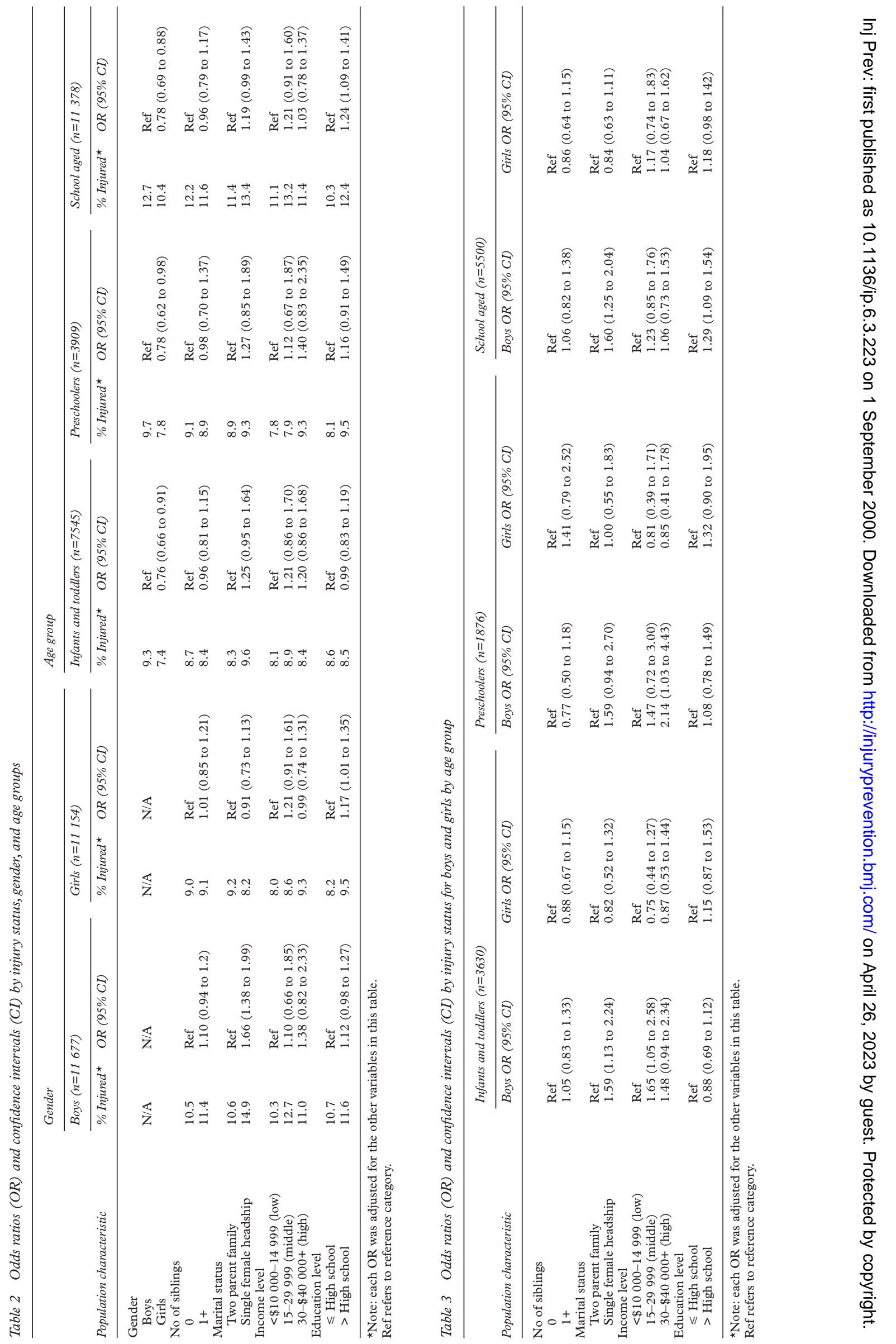


\section{Discussion}

The most numerous childhood injuries are minor injuries, and children who experience numerous mild injuries are likely to experience more severe injuries over time. ${ }^{13}{ }^{14}$ The ability to prevent childhood injury by targeting specific risk factors will affect societal resources, including health care use and missed school days for children and missed workdays for parents.

The strength of survey data is in the collection of detailed injury information about minor injuries not requiring hospitalization. This information is rarely available from other sources. Although maternally reported injuries in the NLSCY are not limited to minor injuries, the majority of the injuries reported were minor in nature. This study examined the patterns and risk factors associated with injuries occurring over a 12 month period using cross sectional data of a nationally representative sample of Canadian children aged $0-11$ years. Information included the cause, type, incidence, and prevalence of injuries.

Our findings based on maternally reported injuries are similar to those reported for more severe forms of injury, such as injury related deaths. ${ }^{21}$ Boys experience more injuries than girls and gender differences increase, as children get older. Boys are more likely to be seen in emergency rooms, more likely to be hospitalized due to injury, and are also more likely to suffer the most severe forms of injury. ${ }^{16712}$ Gender differences may be attributable to boys displaying higher activity levels, ${ }^{22-24}$ engaging in more injury risk behaviours, ${ }^{61325}$ rating injuries as less severe, and attributing injuries to bad luck rather than to their own behaviour. ${ }^{26}{ }^{27}$ Believing that injury results from external causes may deter boys from changing their behaviour or taking precautions to reduce risks in future situations.

Based on maternal reports, the most common forms of injuries for all children are falls. The frequency of falls indicates a developmental pattern, decreasing as children age. This finding is consistent with US studies of emergency room data where the activities leading to non-fatal injuries also vary by child age. Falls represent the major source of severe, nonfatal injuries requiring emergency visits for infants and young children..$^{9-11}$ However, sports and recreational activities are responsible for more emergency visits among school aged children and adolescents.

Patterns of injury reflect both the location and activities where children spend a majority of their time, as well as children's developmental level. As children get older, non-fatal injuries tend to be more severe and are less likely to occur in the home. In this study, $52 \%$ of maternally reported injuries occur in or around the home. This proportion is comparable to the reported number of non-fatal severe injuries $(44.8 \%)$ that occur in the home for children aged $0-20$ years. ${ }^{128}$ The location of injury changes as children spend more time outside the home, particularly during leisure or recreational activities. $^{29}$ For older children, maternal reports of injuries may be underestimated because injuries occurring at school or at daycare may not be reported to parents. ${ }^{30}$

This study found single female headship and maternal education greater than high school to be risk factors for childhood injury. Numerous studies have found maternal education to be inversely associated with risk of injury, ${ }^{15}$ knowledge of risk hazards, and safety behaviours. ${ }^{16}{ }^{17}$ Contrary to studies reporting higher rates of severe childhood injuries with impoverished socioeconomic conditions, ${ }^{15}{ }^{18-20}$ household income was not found to be associated with injury status. Poverty may only be associated with fatal or severe injuries that result in hospitalization. Alternately, poor and less educated families may be under-reporting injuries. A correlation between single female headed families and economic disadvantaged may be influencing these findings. Both single female headship and high household income being associated with injury appears to be inconsistent. However, it is possible that these variables measure different aspects of socioeconomic status, with the former indicating a nonparental care situation, and the latter capturing a different dimension.

\section{LIMITATIONS}

Retrospective maternal recall may err on the side of under-reporting compared with biweekly reporting or reporting by school aged children. ${ }^{30}$ Parents are also more likely to under-report their sons' compared with their daughters' injuries ${ }^{27}$ as boys are less likely to inform their parents. Another limitation of this study is that the data were cross sectional. It is therefore difficult to establish the temporal relationship between injuries and limitations in activities, as mothers did not report if limitations were due to an injury event. Future research, however, should use longitudinal data to assess the direct impact of injuries on the limitations in activities and long term disabilities of children.

\section{Implications for prevention}

Minor injuries occur in approximately $10 \%$ of Canadian children and should not be ignored. Children who suffer injuries, particularly older children, are likely to have limitations in daily activities and to experience increased hospitalizations. Many minor injuries occur in the home and are due to falls and scalds/poisonings, suggesting that parental education in injury prevention skills and child development are important aspects of injury reduction. Parents need to accurately assess children's abilities to judge dangerous situations. The availability and accessibility of information and safe proofing materials for the home would reduce the number of injuries occurring in the home. ${ }^{31} 32$ Findings also suggest that higher household income is associated with minor injuries, whereas low socioeconomic status has been associated with more severe injuries. Therefore the affordability of safety devices may not be the issue, but accessibility, implementation, and the proper use of safety devices is 
important in the prevention of minor childhood injuries.

Sports are frequent causes of injury among school aged children, suggesting that children need to be protected while participating in sporting activities and that sporting environments need to be made safe. Developmental differences in the cause of injury, nature of injury, and body part injured suggest that preventative strategies such as product modifications, educational interventions, and environmental, legislative, and public health policies should take children's developmental level into account. Since injuries occurring away from the home increase with child age, prevention strategies such as education for parents and children need to increase safety knowledge and encourage injury prevention behaviours for children when they are away from home. Policies promoting safe play and safe sporting areas would also be of benefit.

\footnotetext{
This study has been made possible by a financial contribution
from the Office of Injury Prevention, BC Ministry of Health and from the Office of Injury Prevention, BC Ministry of Health and Ministry Responsible for Seniors as well as funding from the
Social Sciences and Research Council and Canadian Institute Social Sciences and Research Council and Canadian Institute
for Advanced Research. The authors would also like to thank for Advanced Research. The auth
the reviewers for their comments.

1 Baker SP, O’Neill B, Karpf RS. The injury fact book. Lexington, MA: Lexington, 1984

2 Budnick LD, Chaiken BP. The probability of dying of injuries by the year 2000. FAMA 1985;254:3350-2.

3 Roberts MC, Brooks PH. Children's injuries: issues in prevention and public policy. F Soc Issues 1987;43(2):1-12

4 Canadian Council on Social Development. The progress of Canada's children. Ottawa: Canadian Council on Social Development, 1996

5 Canadian Institute of Child Health. The health of Canada's children: a statistical profile. Ottawa: Canadian Institute of Child Health, 1994

6 Matheny AP. Accidental injuries. In: Routh D, ed. Handbook of pediatric psychology. New York: Guilford, 1988.

7 Rivara FR, Mueller BA. The epidemiology and causes of childhood injuries. F Soc Issues 1987;43(2):13-31.

8 Baker SP. Motor vehicle occupant deaths in young children. Pediatrics 1979;64:860-1.

9 Gediatrics 1979;64:860-1. Gallagher SS, Finison $\mathrm{K}$, Guyer B, et al. The incidence of
injuries among 87,000 Massachusetts children and injuries among 87,000 Massachusetts children and adolescents: results of the 1980-81 Statewide Childhood
Injury Prevention Program Surveillance System. Am $\mathcal{F}$ Injury Prevention Program Sur
Public Health 1984;10:1340-7.

10 Rivara FP. Developmental and behavioral issues in childhood injury prevention. F Dev Behav Pediatr 1995;16:36270.

11 Rivara FP, Bergman AB, LoGerfo JP, et al. Epidemiology of childhood injuries. II. Sex differences in injury rates. $A m \mathcal{F}$
} Dis Child 1982;136:502-6.
12 BC Ministry of Health. A report on the health of British Columbians. Provincial health officer's annual report. Feature report: The health and well-being of British Columbia's children. Victoria, BC: BC Ministry of Health, 1997.

13 Cataldo MF, Finney JW, Richman GS, et al. Behavior of injured and uninjured children and their parents in a simulated hazardous setting. F Pediatr Psychol 1992;17:73-80.

14 Hartsough CA, Lambert NM. Medical factors in hyperactive and normal children: prenatal, developmental, and health history findings. Am f Orthopsychiatry 1985;55:190201.

15 Beautrais AL, Fergusson DM, Shannon DT. Childhood accidents in a New Zealand birth cohort. Aust Paediatr 7 1982;18:238-42.

16 DiGuiseppi CG, Rivara FP, Koepsell TD. Attitudes toward bicycle helmet ownership adn use by school-age children. Am f Dis Child 1990;144:83-6.

17 Glik D, Kronenfeld J, Jackson K. Safety behaviors among parents of preschoolers. Health Values 1993;17:18.

18 Dowswell T, Towner EML, Simpson G, et al. Preventing childhood unintentional injuries - what works? A literature review. Inj Prev 1996;2:140-9.

19 Nersesian WS, Petit MR, Shaper R, et al. Childhood death and poverty: a study of all childhood deaths in Maine, 1976 to 1980 . Pediatrics $1985 ; 75: 41-50$.

20 Pless IB, Verreault R, Arsenault L, et al. The epidemiology of road accidents in childhood. Am $\mathcal{f}$ Public Health 1987;77:358-60.

21 Vital Statistics Agency. Selected vital statistics and health status indicators. Victoria, BC: BC Ministry of Health, 1996.

22 Bijur PE, Stewart-Brown S, Butler N. Child behavior and accidental injury in 11,966 preschool children. Am 7 Dis Child 1986;140:487-92.

23 Langley J, McGee R, Silva P, et al. Child behavior and accidents. F Pediatr Psychol 1983;8:181-9.

24 Wazana A, Krueger P, Raina P, et al. A review of risk factors for child pedestrian injuries: are they modifiable? Inj Prev 1997;3:295-304.

25 Coppens NM, Gentry LK. Video analysis of playground injury-risk situations. Research in Nursing and Health 1991; 14:129-36.

26 Hillier LM, Morongiello BA. Age and gender differences in school-age children's appraisals of injury risk. F Pediatr Psychol 1998;23:229-38.

27 Morongiello BA. Children's perspectives on injury and close-call experiences: sex differences in injury-outcome processes. F Pediatr Psychol 1997;22:499-512.

28 Kopjar B, Wickizer TM. Population-based study of unintentional injuries in the home. $A m$ f Epidemiol 1996;144:456-62.

29 Soubhi H, Babul S, Chong M. Highlights of unintentional injuries in British Columbia: trends and patterns among children and youth. Vancouver, BC: Centre for Community Child Health Research, 1998.

30 Peterson L, Harbeck C, Moreno A. Measures of children's injuries: self-reported versus maternal-reported events with temporally proximal versus delayed reporting. I Pediatr Psychol 1993;18:133-47.

31 Dershewitz R. Will mothers use free household safety devices? Am f Dis Child 1979;133:61-4.

32 Gallagher S, Hunter P, Guyer B. A home injury prevention program for children. Pediatr Clin North Am 1985;32:95112 . 